\title{
Tracking the rapid loss of tidal wetlands in the Yellow Sea
}

\author{
Nicholas J Murray ${ }^{1,2^{*}}$, Robert S Clemens ${ }^{1}$, Stuart R Phinn ${ }^{3}$, Hugh P Possingham ${ }^{1,4}$, and Richard A Fuller ${ }^{1}$
}

In the Yellow Sea region of East Asia, tidal wetlands are the frontline ecosystem protecting a coastal population of more than 60 million people from storms and sea-level rise. However, unprecedented coastal development has led to growing concern about the status of these ecosystems. We developed a remote-sensing method to assess change over $\sim 4000 \mathrm{~km}$ of the Yellow Sea coastline and discovered extensive losses of the region's principal coastal ecosystem - tidal flats - associated with urban, industrial, and agricultural land reclamations. Our analysis revealed that $28 \%$ of tidal flats existing in the 1980 s had disappeared by the late 2000 s (1.2\% annually). Moreover, reference to historical maps suggests that up to $65 \%$ of tidal flats were lost over the past five decades. With the region forecast to be a global hotspot of urban expansion, development of the Yellow Sea coastline should pursue a course that minimizes the loss of remaining coastal ecosystems.

Front Ecol Environ 2014; 12(5): 267-272, doi:10.1890/130260 (published online 8 May 2014)

$\mathrm{H}_{\mathrm{c}}^{\mathrm{u}}$ uman populations are increasing exponentially in coastal regions worldwide, rendering nearly 200 million people vulnerable to severe weather events and sea-level rise (Small and Nicholls 2003). Many of the world's most densely populated coasts are fringed by protective tidal flats that stabilize coastlines, defend against storm surges, and provide economic opportunities to human communities (Healy et al. 2002; Nicholls et al. 2007). With exceptionally high biodiversity supported by both terrestrial- and marine-derived nutrients, tidal flats are among the world's most productive ecosystems, acting as nurseries for finfish and shellfish, and as habitat for tens of millions of migratory birds (MA 2005). However, recent reports of substantial reductions of sediment delivery from major rivers (Syvitski et al. 2005), sinking of river deltas (Syvitski et al. 2009), coastal erosion (Nicholls et al. 2007), and widespread degradation from coastal development (Kirwan and Megonigal 2013) indicate that coastal ecosystems are under extreme stress, yet the changing status of tidal flats beyond local scales remains largely unknown.

Such paucity of knowledge stems from the fact that tidal flats are fully exposed only at low tide, which hinders detection of change in their extent over large areas. We developed a method to resolve this by mapping longterm change of tidal ecosystems using publicly available

${ }^{1}$ Australian Research Council Centre of Excellence for Environmental Decisions, School of Biological Sciences, University of Queensland, St Lucia, Australia*(murr.nick@gmail.com); ${ }^{2}$ CSIRO Climate Adaptation Flagship and CSIRO Ecosystem Sciences, Dutton Park, Australia; ${ }^{3}$ Centre for Spatial Environmental Research, School of Geography, Planning and Environmental Management, University of Queensland, St Lucia, Australia; Imperial College London, Department of Life Sciences, Silwood Park, Ascot, UK time-series satellite imagery. With additional reference to historical topographic maps, here we report on more than 50 years of change in tidal flat extent for $\sim 4000 \mathrm{~km}$ of East Asia's Yellow Sea coastline.

Tidal wetlands in the Yellow Sea are dominated by tidal flats that, at up to $20-\mathrm{km}$ wide, are among the most extensive in the world (Healy et al. 2002), providing an estimated $\$ 30$ billion per year in ecosystem services (MacKinnon et al. 2012) and buffering one of the most densely populated coastal areas in the world from storms and sea-level rise (Small and Nicholls 2003; Nicholls et al. 2007). The Yellow Sea's low-elevation coastal zone is home to about 60 million people, and unprecedented urban, industrial, and agricultural expansion in the region has led to concern about coastal ecosystem integrity and imperiled species conservation (CIESIN 2005; MacKinnon et al. 2012). With the Yellow Sea coastal zone projected to be part of a $1800-\mathrm{km}-\mathrm{long}$ urban corridor by 2030 (Seto et al. 2012), there is an urgent need to understand the distribution and status of remaining coastal ecosystems to allow the development of complementary conservation and land-use planning strategies.

We mapped the extent of tidal flats across the three countries with a Yellow Sea coastline - China, North Korea, and South Korea - at three time periods (mid1950s, early 1980s, and late 2000s). The analysis was conducted on 80 Landsat Archive images in two clusters (early 1980s and late 2000s) and 25 digitized 1:250 000 topographic maps (mid-1950s) across $\sim 4000 \mathrm{~km}$ of coastline between northern Jiangsu province, China $\left(34^{\circ} 29^{\prime} \mathrm{N}, 119^{\circ} 47^{\prime} \mathrm{E}\right)$ and eastern Busan province, South Korea $\left(35^{\circ} 20^{\prime} \mathrm{N}, 129^{\circ} 17^{\prime} \mathrm{E}\right.$; Figure 1). Here, we report on areal changes of tidal flats over timescales and spatial extents that have hitherto been impossible to study. 


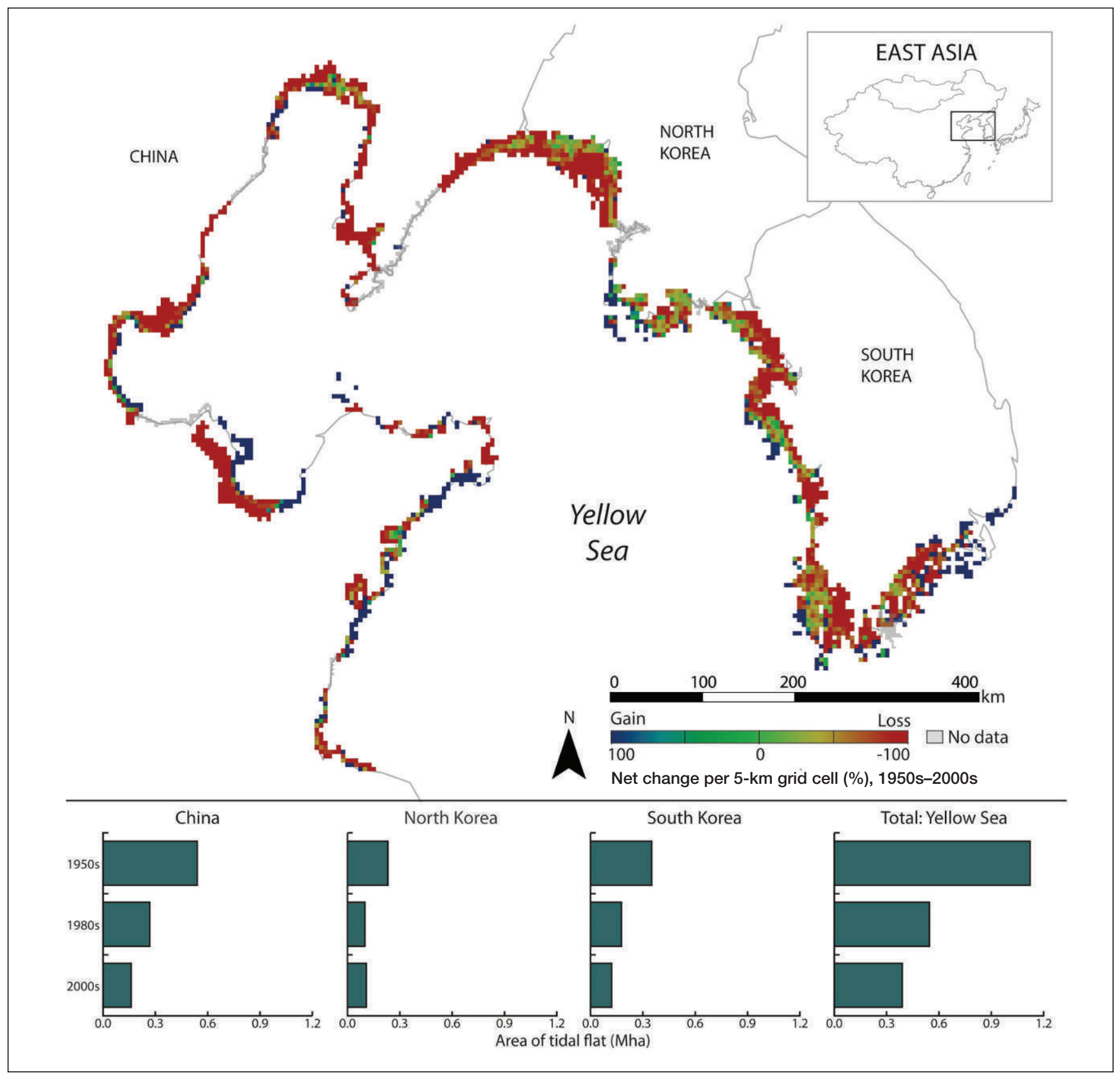

Figure 1. Change in tidal flats in the Yellow Sea between the 1950s and the 2000s, mapped at a 5-km grid resolution. Net change between the two time periods is shown on a color ramp from blue (total gain) to red (total loss).

\section{Materials and methods}

\section{Satellite data and topographic maps}

Using the Oregon State University China Seas tide model (Egbert and Erofeeva 2002), we first estimated the tidal elevation at the time of acquisition for all Landsat Archive images available for the Yellow Sea coastal region (5568 images). We visually reviewed all Landsat Archive images that were acquired within the upper and lower $10 \%$ of the tidal range and selected an image set composed of images suitable for the subsequent remotesensing analysis (Murray et al. 2012). The final image set comprised 32 ETM+ (Enhanced Thematic Mapper Plus),
12 Landsat TM (Thematic Mapper), and 36 Landsat MSS (Multi-Spectral Scanner) satellite images across 20 Landsat $185-\mathrm{km} \times 170-\mathrm{km}$ footprints (path-row tiles), with images including areas with macro $(>4 \mathrm{~m})$, meso $(2-4 \mathrm{~m})$, and micro $(<2 \mathrm{~m})$ tidal ranges (mean tide range $2.45 \mathrm{~m}$ ) (WebTable 1). For each Landsat scene, we used image differencing of classified land-water images to map the area between the high-and low-tide waterline in each time period, resulting in spatial datasets of tidal flats present in the 1980s and 2000s (Murray et al. 2012).

To assess the accuracy of each tidal flat dataset, we adopted a widely used accuracy assessment protocol termed an error matrix (Congalton and Green 2008). An independent analyst was offered 240 randomly generated points over the 
study area for each dataset and was required to classify each point as either tidal flat or other, using the low-tide satellite image set for the period in question (Murray et al. 2012). The analyst was able to use all available bands of the Landsat imagery to decide whether a point was a tidal flat. The resulting dataset of validation points, when compared with our classification points, allowed the error matrix for each period to be populated (WebTables 2 and 3). The accuracy assessment revealed $>94 \%$ overall classification accuracy for mapping tidal flats with Landsat Archive imagery.

For a historical baseline, we digitized 25 coastal maps available from the AMS L500 (China), L541 (Manchuria), and L552 (Korea) series of 1:250 000 topographic maps (US Army Map Service 1962). The collection was produced between 1950 and 1962, and depicts tidal flats to a smallest patch size of approximately $250 \mathrm{~m} \times 250 \mathrm{~m}$. All of the maps contained reliability diagrams indicating their origin, which included large-scale topographic maps, and photogrammetric and hydrographic sources. We georeferenced the topographic maps against prominent topographical features in terrain-corrected Landsat imagery and delineated the foreshore flat class using interactive digitization methods (Hood 2004; Hughes et al. 2006). Given their level of detail, the inclusion of reliability diagrams, information on their source data, and the overlap with our Landsatderived datasets (Figure 2), we considered this dataset a valuable historical baseline.

\section{Change detection}

To permit comparison across the three time periods (1950s, 1980s, 2000s), we resampled each dataset to 250-m spatial resolution, which was larger than the smallest patch of tidal flat depicted in the topographic maps, and then reprojected each dataset to an Albers Equal Area projection. We also accounted for the 2003 failure of the Scan Line Corrector (SLC) aboard the Landsat 7 satellite, which resulted in data gaps (striping) for approximately $26 \%$ of the tidal flat area in the 2000s dataset. Areas of images lost due to the SLC failure were overlaid onto the complete 1980s dataset, allowing change between the two datasets to be calculated. Thus, the 2000s extent of tidal flat $\left(A_{2}\right)$ is calculated as

$$
A_{2}=A_{1}\left\{1-\left[\left(A_{h}-A_{p}\right) / A_{h}\right]\right\}
$$

where $A_{1}$ is the 1980 s extent of tidal flats, $A_{p}$ is the 2000 s dataset (with SLC-off data gaps), and $A_{h}$ is the artificially
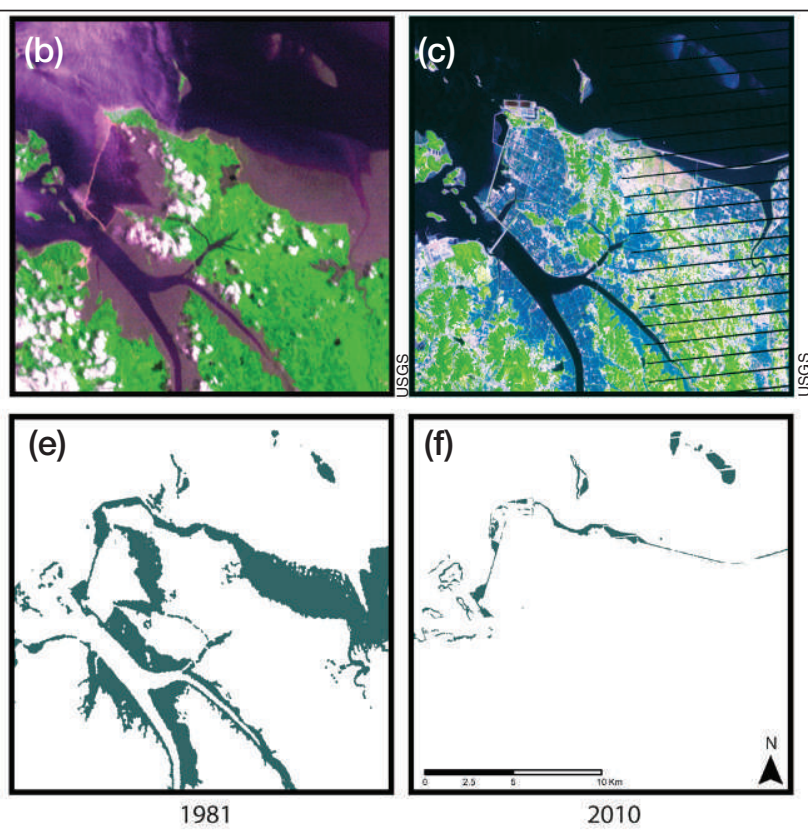

1981

2010

Figure 2. An example of tidal flat mapping results, showing the raw data $(a-c)$ and mapped tidal flats $(d-f)$. The results reveal widespread loss of tidal flats from 1954 (left) to 2010 (right). Satellite images (b) and (c) show that tidal flats present in 1981 (e) were reclaimed for agricultural and industrial land by 2010 (f).

striped $A_{1}$ dataset. Lastly, areas that could not be mapped in one time period, primarily because of chronic cloud or ice cover, were masked over all three datasets, resulting in final coverage of $87.9 \%$ of the study area coastline (Figure 1).

We established the total area of each of the three tidal flat datasets and calculated the net change over the study region between each of the time periods (1950s-1980s, 1980s-2000s, 1950s-2000s; Table 1). We also calculated the continuous rate of change $\left(r, \% \mathrm{yr}^{-1}\right)$ of tidal flats on a per Landsat footprint basis between each of the time periods as

$$
r=\left[1 /\left(t_{2}-t_{1}\right)\right] \times \ln \left(\mathrm{A}_{2} / \mathrm{A}_{1}\right)
$$

where $A_{1}$ and $A_{2}$ are the areas of tidal flats in a Landsat footprint at times $t_{1}$ and $t_{2}$, respectively.

\section{Results and discussion}

Our analysis of the change in areal extent of tidal flats in the Yellow Sea indicates that of the 545000 ha present in the 1980s, only 389000 ha remained three decades later, equating to a net loss of $28 \%$ at a mean rate of $-1.2 \% \mathrm{yr}^{-1}$ (Table 1). Comparing the three countries in our analysis, China lost more tidal flat area and at a faster rate $(39.8 \%$, $\left.-1.8 \% \mathrm{yr}^{-1}\right)$ than South Korea $\left(32.2 \%,-1.6 \% \mathrm{yr}^{-1}\right)$; in North Korea, minor gains of tidal flats occurred $(8.5 \%$, $\left.0.3 \% \mathrm{yr}^{-1}\right)$. Our area-related values underestimate the full tidal flat extent in the Yellow Sea, because cloud cover, ice cover, and lack of images acquired at suitable tide heights precluded mapping $12.1 \%$ of the study area coastline (Figure 1). Nevertheless our data cover $>4000 \mathrm{~km}$ of the Yellow Sea coastline and reveal rapid and widespread 

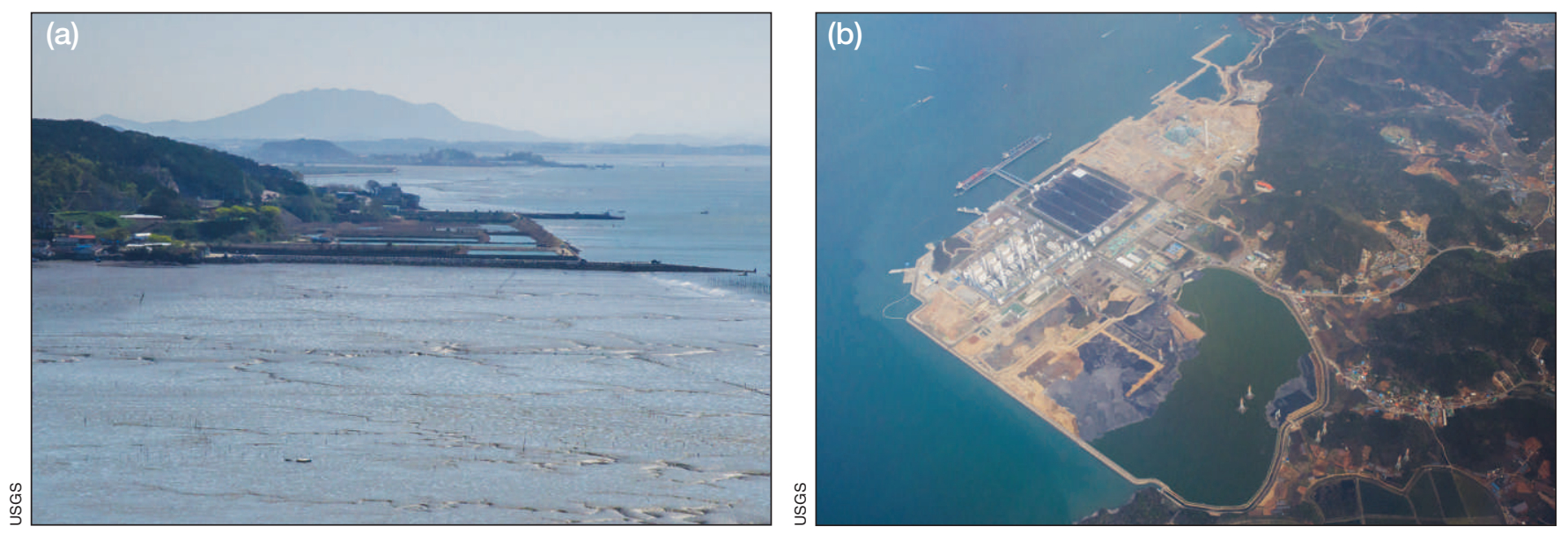

Figure 3. Tidal flat conversion to alternative land uses. (a) Aquaculture development encroaching approximately $250 \mathrm{~m}$ onto a tidal flat (top of image) in Gomso Bay, South Korea. (b) Coastal reclamation for industrial land at an offshore island in South Korea, noting the ships in port at the top left for scale.

declines of tidal flats across the entire region (Figure 1; Table 1).

According to historical topographic maps, tidal flats occupied 1.12 million ha in the mid-1950s, equating to a potential net loss of up to $65 \%$ over 50 years (Table 1 ). Comparisons with historical mapping must of course be interpreted cautiously, although we took care to match the resolution of the three datasets and thoroughly investigated the reliability of the maps. Thus, our results suggest that up to two-thirds of the tidal flats existing around the Yellow Sea in the 1950s have since vanished, with losses in China and South Korea accounting for most of the decline (Figure 1; Table 1).

Losses of tidal flats were spatially pervasive, occurring throughout heavily populated and rapidly developing coastal areas (Figure 1). Tidal flats increased in extent in a few isolated locations, such as the seaward edge of several coastal embayments and at growing river deltas. Much of the Yellow Sea coastline is under intense pressure from land claims (commonly termed reclamation) for agriculture, aquaculture, and industrial development (Figures 2 and 3). For example, agricultural development in Chungcheongnam-do Province, South Korea, caused the loss of more than 7000 ha of tidal flats over the past 30 years (Figure 2 ). Two developments currently underway - Saemangeum, South Korea (40100 ha) and the
Caofeidian port development in China (31000 ha; WebFigure 1) - are among the largest reclamation projects on Earth (CCICED 2010; MacKinnon et al. 2012). Similarly, the conversion of tidal flats to aquaculture ponds is widespread in the Yellow Sea and, with Asia currently supplying $89 \%$ of global aquaculture production (FAO 2012), further reclamation of tidal flats will be required to meet increasing demand (Naylor et al. 2000). The impact of reclamation activity on tidal flats is also reflected in our results for North Korea, where the near absence of recent coastal development allowed minor gains in tidal flat extent. This appears to result from sediment deposition in the estuaries of the Yalu and Chongchon rivers, perhaps owing to increased soil erosion caused by abrupt land clearing that occurred in North Korea during the 1990s (Stone 2012).

Tidal flats may be expected to shift seaward over the long term in response to reclamation activities (Hood 2004; Kirwan and Megonigal 2013), but our data indicate that this is not happening at a rate sufficient to compensate for the loss, probably as a result of local compaction and appropriation of tidal flat sediments for construction purposes (MacKinnon et al. 2012). Studies of salt marsh systems have shown that changes in sediment supply and loss of coastal vegetation can lead to collapse of tidal wetlands, resulting in a runaway effect of tidal flat deepening and bed erosion (Kirwan and Megonigal 2013; Mariotti and Fagherazzi 2013). Yellow Sea tidal flats are highly dependent on ongoing sediment supply (Healy et al. 2002) and substantial declines of sediment output from major rivers in the region, such as the $90 \%$ decline in sediment flow from the Yellow River during the 20th century (Syvitski et al. 2009; Wang et al. 2010), could be contributing 
to the broad-scale losses that we detected Consequently, although we consider coastal reclamation to be an important driver of tidal flat losses in the Yellow Sea, processes such as changes in sediment supply, loss of coastal vegetation associated with development, erosion, redistribution of sediments due to storms, and compaction and subsidence (sinking) caused by extensive subsurface resource and groundwater extraction are also likely to be operating (Bartholdy and Aagaard 2001; Syvitski et al. 2009; Nicholls and Cazenave 2010; Higgins et al. 2013). These factors could increase vulnerability of coastal communities and coastal developments to storms and sea-level rise, because land reclamations, intensive extractive activities, and sediment declines have been shown to lead to relative sea-level rise that can be several orders of magnitude greater than background levels of local and global sea-level rise ( $\mathrm{Li}$ et al. 2004; Cazenave and Le Cozannet 2013; Higgins et al. 2013).

Although the magnitude of losses is alarming, our results broadly agree with several other information sources on coastal wetland loss in East Asia. For instance, the China Council for International Cooperation on Environment and Development reported that China has lost $57 \%$ of its coastal wetlands since the 1950s, and that more than 1.3 million ha of coastal reclamation occurred between 1990 and 2008 (CCICED 2010). Other sources suggest that $51 \%$ of coastal wetlands in China were lost over the past 50 years (An et al. 2007), that more than one-third of China's tidal flats were reclaimed between 1950 and 1985 (Yu 1994), and that half of South Korea's tidal wetlands have been reclaimed in the past 50 years (Cho and Olsen 2003). With the implementation of a robust, repeatable remote-sensing framework, our results provide the first quantitative verification of widespread declines of tidal flats in the Yellow Sea region. Globally, the status and distribution of tidal flats remain poorly understood, and with about one-third of vegetated coastal ecosystems - including mangroves, seagrass beds, and salt marshes - estimated to have been lost in the past few decades (Mcleod et al. 2011), the total loss of tidal flats could be equally as high. Our method for mapping tidal flats permits detailed measurement of tidal habitats over thousands of kilometers, and could provide a practical solution for establishing the status of tidal wetlands for any large geographic region.

\section{Conclusions}

Our analysis indicates that tidal flats along the Yellow Sea are declining at a rate comparable to many other atrisk ecosystems, such as tropical forests (Achard et al. 2002), seagrass meadows (Waycott et al. 2009), and mangroves (Giri et al. 2011). None of the drivers we identify are unique to this region of the world. Degradation and reclamation of coastal wetlands are worldwide phenomena (MA 2005) and are likely to intensify, owing to the increasing scarcity of land in coastal areas and the low cost and rapid pace at which these areas can be developed (MacKinnon et al. 2012). Similarly, reduced sediment discharge, often associated with trapping of sediments in reservoirs, is associated with land loss at 26 of the world's major river deltas (Syvitski et al. 2009). These factors, when combined with coastal subsidence due to resource extraction and coastal development, result in relative sea-level rise in coastal regions that is far greater than the rate of global sea-level rise, potentially leading to further loss of tidal flat ecosystems (Cazenave and Le Cozannet 2013).

A combination of accelerating human population growth along the world's coastlines and impacts expected from sea-level rise suggest that unless prompt action is taken to protect remaining tidal wetlands, coastlines and their associated ecosystem services will become increasingly vulnerable in the 21st century. Major systems of tidal flats protect 15 of the world's 20 most flood-vulnerable coastal cities (WebTable 4), and their maintenance and protection offers an additional method for shielding these communities from the impacts of storms and sealevel rise (Arkema et al. 2013). Early warning signs from the Yellow Sea suggest that the consequences of intertidal ecosystem loss for coastal biodiversity may already be apparent. Of the six migratory shorebird species that depend solely on Yellow Sea tidal flats during migration, the great knot (Calidris tenuirostris) and the far eastern curlew (Numenius madagascariensis) have recently been listed as globally threatened by the IUCN. In the Yellow Sea region, where substantial urban expansion is forecast in coastal areas, safeguarding ecosystem services provided by tidal flats and ensuring protection of the region's coastal biodiversity will require coastal development strategies that minimize ecosystem loss and protect remaining coastal ecosystems.

\section{Acknowledgements}

We thank M Choi, R Ferrari, T Gill, J Hanson, D Melville, C Roelfsema, and V Wingate for assistance with various components of the project, and D Watkins, N Moores, and the East Asian-Australasian Flyway Partnership for regional expertise. This project was supported by an Australian Research Council Linkage Grant LP100200418, co-funded by the Queensland Department of Environment and Resource Management; Commonwealth Department of the Environment; the Queensland Wader Study Group; and the Port of Brisbane Pty Ltd. Additional support was provided by Birds Queensland and the CSIRO Climate Adaptation Flagship. Landsat data are available from the US Geological Survey.

\section{References}

Achard F, Eva HD, Stibig H-J, et al. 2002. Determination of deforestation rates of the world's humid tropical forests. Science 297: 999-1002.

An SQ, Li HB, Guan BH, et al. 2007. China's natural wetlands: 
past problems, current status, and future challenges. Ambio 36: $335-42$.

Arkema KK, Guannel G, Verutes G, et al. 2013. Coastal habitats shield people and property from sea-level rise and storms. Nature Clim Change 3: 913-18.

Bartholdy J and Aagaard T. 2001. Storm surge effects on a backbarrier tidal flat of the Danish Wadden Sea. Geo-Mar Lett 20: $133-41$.

Cazenave A and Le Cozannet G. 2013. Sea level rise and its coastal impacts. Earth's Future 2: 15-34.

CCICED (China Council for International Cooperation on the Environment and Development). 2010. The sustainable development of China's ocean and coasts: ecological issues and policy recommendations. Beijing, China: CCICED.

Cho DO and Olsen SB. 2003. The status and prospects for coastal management in Korea. Coast Manage 31: 99-119.

CIESIN (Center for International Earth Science Information Network). 2005. Gridded population of the world, version 3. http://sedac.ciesin.columbia.edu/data/set/gpw-v3-populationdensity. Viewed 14 Feb 2014.

Congalton RG and Green K. 2008. Assessing the accuracy of remotely sensed data: principles and practices. London, UK: CRC Press.

Egbert GD and Erofeeva SY. 2002. Efficient inverse modeling of barotropic ocean tides. Atmos Ocean Tech 19: 183-204.

FAO (UN Food and Agriculture Organization). 2012. The state of world fisheries and aquaculture 2012. Rome, Italy: FAO.

Giri C, Ochieng E, Tieszen L, et al. 2011. Status and distribution of mangrove forests of the world using Earth observation satellite data. Global Ecol Biogeogr 20: 154-59.

Healy T, Wang Y, and Healy J (Eds). 2002. Muddy coasts of the world: processes, deposits, and function. Amsterdam, the Netherlands: Elsevier Science.

Higgins S, Overeem I, Tanaka A, et al. 2013. Land subsidence at aquaculture facilities in the Yellow River Delta, China. Geophys Res Lett 40: 3898-902.

Hood WG. 2004. Indirect environmental effects of dikes on estuarine tidal channels: thinking outside of the dike for habitat restoration and monitoring. Estuaries 27: 273-82.

Hughes ML, McDowell PF, and Marcus WA. 2006. Accuracy assessment of georectified aerial photographs: implications for measuring lateral channel movement in a GIS. Geomorphology 74: 1-16.

Kirwan ML and Megonigal JP. 2013. Tidal wetland stability in the face of human impacts and sea-level rise. Nature 504: 53-60.

Li C, Fan D, Deng B, et al. 2004. The coasts of China and issues of sea level rise. J Coastal Res 43: 36-49.

MA (Millennium Ecosystem Assessment). 2005. Ecosystems and human well-being: current state and trends. Washington, DC: Island Press.
MacKinnon J, Verkuil YI, and Murray NJ. 2012. IUCN situation analysis on East and Southeast Asian intertidal habitats, with particular reference to the Yellow Sea (including the Bohai Sea). Occasional Paper of the IUCN Species Survival Commission No 47. Gland, Switzerland; Cambridge, UK: IUCN.

Mariotti G and Fagherazzi S. 2013. Critical width of tidal flats triggers marsh collapse in the absence of sea-level rise. P Natl Acad Sci USA 110: 5353-56.

Mcleod E, Chmura GL, Bouillon S, et al. 2011. A blueprint for blue carbon: toward an improved understanding of the role of vegetated coastal habitats in sequestering $\mathrm{CO}_{2}$. Front Ecol Environ 9: 552-60.

Murray NJ, Phinn SR, Clemens RS, et al. 2012. Continental scale mapping of tidal flats across East Asia using the Landsat Archive. Remote Sens 4: 3417-26.

Naylor RL, Goldburg RJ, Primavera JH, et al. 2000. Effect of aquaculture on world fish supplies. Nature 405: 1017-24.

Nicholls RJ and Cazenave A. 2010. Sea-level rise and its impact on coastal zones. Science 328: 1517-20.

Nicholls RJ, Wong PP, Burkett VR, et al. 2007. Coastal systems and low-lying areas. In: Parry ML, Canziani OF, Palutikof JP, et al. (Eds). Climate change 2007: impacts, adaptation and vulnerability. Contribution of Working Group II to the Fourth Assessment Report of the Intergovernmental Panel on Climate Change. Cambridge, UK: Cambridge University Press.

Seto KC, Güneralp B, and Hutyra LR. 2012. Global forecasts of urban expansion to 2030 and direct impacts on biodiversity and carbon pools. P Natl Acad Sci USA 109: 16083-88.

Small C and Nicholls RJ. 2003. A global analysis of human settlement in coastal zones. J Coastal Res 19: 584-99.

Stone R. 2012. Seeking cures for North Korea's environmental ills. Science 335: 1425-26.

Syvitski JPM, Kettner AJ, Overeem I, et al. 2009. Sinking deltas due to human activities. Nat Geosci 2: 681-86.

Syvitski JPM, Vörösmarty CJ, Kettner AJ, et al. 2005. Impact of humans on the flux of terrestrial sediment to the global coastal ocean. Science 308: 376-80.

US Army Map Service. 1962. 1:250 000 topographic maps (series L500, L542, L552). Washington, DC: Army Maps Service. www.lib.utexas.edu/maps/ams/index.html. Viewed 24 Mar 2014.

Wang HJ, Bi NS, Saito Y, et al. 2010. Recent changes in sediment delivery by the Huanghe (Yellow River) to the sea: causes and environmental implications in its estuary. J Hydrol 391: 302-13.

Waycott M, Duarte CM, Carruthers TJB, et al. 2009. Accelerating loss of seagrasses across the globe threatens coastal ecosystems. P Natl Acad Sci USA 106: 12377-81.

Yu H. 1994. China's coastal ocean uses: conflicts and impacts. Ocean Coast Manage 25: 161-78.

\section{TAKE THIS JOURNAL TO YOUR LIBRARIAN, PLEASE}

Are you enjoying this issue of Frontiers?

If your library had a subscription, colleagues and students could enjoy it too.

ot:

Please consider recommending Frontiers in Ecology and the Environment to your library. Clip or copy the form below. Thank you for your support.

Library Recommendation Form

To Acquisition Librarian, Serials

From

Dept

Signature Date

I recommend the library subscribe to: Frontiers in Ecology and the Environment (ISSN 1540-9295)

To request a free sample issue of Frontiers in Ecology and the Environment, email Eric Gordon at eric@esa.org.

Order Frontiers by contacting ESA Headquarters at (202) 833-8773, online at www.esa.org, or through your subscription agent. 